\title{
Paraoxonase single nucleotide variants show associations with polycystic ovary syndrome: a meta-analysis
}

\author{
Anthicha Kunjantarachot ${ }^{1}$, Noel Pabalan ${ }^{1 *} \mathbb{D}$, Hamdi Jarjanazi ${ }^{2}$, Denise Maria Christofolini ${ }^{3}$, Erik Montagna ${ }^{3}$,
} Caio Parente Barbosa ${ }^{3}$ and Bianca Bianco ${ }^{3}$

\begin{abstract}
Background: Etiology of polycystic ovary syndrome (PCOS) is attributed to genetic and environmental factors. One environmental factor is oxidative stress. Paraoxonase 1 (PON1) is an antioxidant high-density lipoprotein-associated enzyme encoded by the PON1 gene. The PON1 gene has been implicated in the risk for PCOS, the influence of which appears to come from single nucleotide variants (SNVs) at multiple genetic loci. However, association study reports have been inconsistent which compels a meta-analysis to obtain more precise estimates.

Methods: From 12 publications, extracted genotype data were used in two genetic procedures. First, linkage disequilibrium (LD) was used to group eight PON SNVs into three: LD1, LD2 and LD3. Second, frequencies of the variant (var), wild-type (wt) and heterozygous (het) genotypes were used for genetic modeling (allele-genotype for LD1 and standard for LD2 and LD3). Risk associations were expressed in terms of pooled odds ratios (ORs), 95\% confidence intervals $(\mathrm{Cls})$ and $P^{\mathrm{a}}$-values. Evidence was considered strong when significance was high $\left(P^{\mathrm{a}}<0.0001\right)$ and heterogeneity absent $\left(l^{2}=0 \%\right)$. Pooled effects were subjected to modifier (power), subgroup (Asian/Caucasian), outlier, sensitivity and publication bias treatments. Multiple comparisons were Bonferroni-corrected.

Results: This meta-analysis generated 11 significant outcomes, five in LD1, six in LD2 and none in LD3. All six LD2 outcomes did not survive the Bonferroni-correction but two of the five in LD1 did. These two core LD1 findings conferred greater odds of PCOS to the var allele in the highly significant $\left(P^{\mathrm{a}}<0.0001\right)$ overall $(\mathrm{OR} 1.44,95 \% \mathrm{Cl} 1.24-$ 1.67) and Asian (OR 1.41, 95\% Cl 1.20-1.65) outcomes. Of these two core outcomes, the Asian effect was homogeneous $\left(1^{2}=0 \%\right)$ but not the overall $\left(1^{2}=29 \%\right)$.

Conclusions: Of the eight PON SNVs examined, two (rs854560 and rs662) were associated with PCOS risk. These 1.4-fold increased risk effects rendered Asians susceptible to PCOS. High statistical power, high significance, zero to low-level heterogeneity, robustness and lack of bias in the core outcomes underpinned the strong evidence for association.
\end{abstract}

Keywords: PON, Paraoxonase, Single nucleotide variants, PCOS, Meta-analysis

\footnotetext{
* Correspondence: noelpabalan@mail.com

${ }^{1}$ Chulabhorn International College of Medicine, Thammasat University, Khlong Luang District, Rangsit, Pathumthani, Thailand

Full list of author information is available at the end of the article
}

(c) The Author(s). 2020 Open Access This article is licensed under a Creative Commons Attribution 4.0 International License, which permits use, sharing, adaptation, distribution and reproduction in any medium or format, as long as you give appropriate credit to the original author(s) and the source, provide a link to the Creative Commons licence, and indicate if changes were made. The images or other third party material in this article are included in the article's Creative Commons licence, unless indicated otherwise in a credit line to the material. If material is not included in the article's Creative Commons licence and your intended use is not permitted by statutory regulation or exceeds the permitted use, you will need to obtain permission directly from the copyright holder. To view a copy of this licence, visit http://creativecommons.org/licenses/by/4.0/ The Creative Commons Public Domain Dedication waiver (http://creativecommons.org/publicdomain/zero/1.0/) applies to the data made available in this article, unless otherwise stated in a credit line to the data. 


\section{Introduction}

Polycystic ovary syndrome (PCOS) is a multifactorial and polygenic disorder [1]. Genetic and environmental factors have a marked influence on the progression of PCOS [2]. Oxidative stress is an environmental factor that plays an important role in the pathogenesis of PCOS [3] and has become the focus of genetic association studies [4,5] where single nucleotide variants (SNVs) in genes with anti-oxidant function, like paraoxonase 1 (PON1), have been implicated [6]. The PON1 gene, located on chromosome 7q21.3, is composed of eight introns and nine exons spanning $26 \mathrm{~kb}$ and is a member of a multi-gene cluster including PON1, PON2 and PON3 [7]. All three PON genes lie on the long arm of chromosome 7 (7q21-22). PON1 lies near the centromere, while PON2 is near the telomere with $P O N 3$ in between them [8]. The PON2 SNV, rs7493 (Ser311Cys), is a substitution of guanine to cytosine nucleotides that results in serine to cysteine amino acid substitutions at residue 311 [9]. Studies have also revealed other SNVs in the PON gene cluster $[10,11]$. Several SNVs in PON1 have been studied in regard to its enzyme activity and risk of diseases including PCOS [12]. Among them are five in the promoter region: (i) rs854572 (g.95325384C > G), (ii) rs705381 (g.95324637 T > C), (iii) rs705379 (g.95324583G > A), (iv) rs854571 (g.95325307 T > C) and (v) rs854573 (g.95325551C > T) and two in the coding region (exon 6 and exon 3, respectively): (i) rs662 (c.575A > G, Gln192Arg) and (ii) rs854560 (c.163 T > A, Leu55Met) $[13,14]$. These PON1 variants (var) have been reported to regulate PON1 expression and affect circulating serum levels as well as catalytic activity [13, 15]. The rs705379 polymorphism partially regulates PON1 expression [16] by modulating the binding site for Sp1transcription factor $[13,17]$ while the rs705381 lies in a potential NF-1 transcription factor binding site [13]. PON1 polymorphisms have been investigated in a variety of pathophysiological conditions that range from metabolic syndrome, cardiovascular diseases and stroke to diabetes. These reports collectively enabled better understanding of the genetic (in terms of transcription factor binding capacity and gene expression level) and physiological pathways conferring the importance of SNVs in oxidative regulation related to the etiology of PCOS. However, associations of the PON SNVs with PCOS risk have been contradictory, which gives reason to perform a meta-analysis of all eligible studies. Since the four previous meta-analyses [18-21], new primary studies have emerged. We provide a more comprehensive analysis and arrive at a reliable conclusion by reevaluating the associations of the $P O N$ SNVs with PCOS risk. To this end, we apply a number of meta-analytical tools that yields fresh insight in the PON-PCOS associations.

\section{Materials and methods}

\section{Selection of studies}

We searched MEDLINE using PubMed, Science Direct and Google Scholar for association studies as of August 03, 2019. The terms used were "PON", "paraoxonase", "polymorphisms", "polycystic ovary syndrome" and "PCOS" as medical subject heading and text, unrestricted by language and time span. References cited in the retrieved articles were screened manually for additional eligible studies. Inclusion criteria were: (i) case-control studies evaluating the association between $P O N$ variants and PCOS and (ii) genotype frequency data to calculate odds ratios (ORs) and 95\% confidence intervals (CIs). Exclusion criteria were: (i) animal studies, (ii) reviews, case report or case series, expert opinion and (iii) unusable genotype data.

\section{Data extraction}

Two investigators (AK and NP) independently extracted data and arrived at consensus. The following information was obtained from each publication: indications (yes/no) of whether each article was included in the four previous meta-analyses [18-21], first author's name, published year, country of origin, ethnicity, diagnostic criteria, PON SNVs examined and article features needed to tally the Clark-Baudouin score. Table S1 shows the rs numbers (SNVs per study), values under cases and controls that include sample sizes and genotype frequencies as well as minor allele frequencies and $P$-values for the Hardy-Weinberg Equilibrium (HWE).

\section{Statistical power, HWE and data distribution}

We used the G*Power program [22] to evaluate statistical power, where adequacy was set at $\geq 80 \%$ assuming an OR of 1.5 and a genotypic risk level of $\alpha=0.05$. Control frequencies from the HWE were calculated from https://ihg.gsf.de/cgi-bin/hw/hwa1.pl with a two-tailed $P<0.05$ indicating deviations. Data distribution was assessed with the Shapiro-Wilk test [23].

\section{Quality assessment of the studies}

Methodological quality of the included articles was assessed with the Clark-Baudouin scale [24], the scores of which range from 0 (worst) to 10 (best) where $<5,5-$ 7 and $>7$ indicate low, moderate and high, respectively.

\section{Meta-analysis}

Linkage disequilibrium (LD) and genetic modeling

We performed LD analysis and adopted a suitable genetic model before examining associations of the $P O N$ SNVs with risk of PCOS. Proximity of SNVs has been posited to cause observed phenotype associations [25] and could merit grouping. Rationale for SNV grouping lies in the concept that SNVs in high LD are assumed to 
have similar association outcomes. $\mathrm{D}^{\prime}$ is the metric for LD, in which a value of 1 indicated complete LD [26]. Eight PON SNVs were grouped into three (Table S1) based on D' values of $0.97-1.00$ as LD1 (rs854560 and rs662), LD2 (rs705379, rs7493 and rs854572) and LD3 (rs705381, rs854571, rs854572 and rs854573). Because multiple SNVs had different notations for each genotype, we notated variant and wild-type as var and $w t$, respectively. Uniformity of the minor allele frequency (all <0.50) values across the studies in LD2 and LD3 merited use of standard genetic models: (i) recessive: var-var versus het $+w t$-wt, (ii) dominant: var-var + het versus $w t$-wt and (iii) codominant: var versus $w t$ [27]. Because of non-uniformity of the minor allele frequencies for LD1, we compared the following: (i) var allele with var-wt/wt-wt genotypes, (ii) $w t$ allele with var-wt/ $w t$-wt genotypes and (iii) $w t$-var (heterozygous) genotype with homozygous $w t$-wt and var-var genotypes.

\section{Data synthesis}

Risk association assessments were confined to HWEcompliant studies [28]. Using raw genotype frequency data, study-specific risks (ORs) of PCOS were estimated and pooled ORs and 95\% CIs were calculated by comparing the effects on the same baseline. Associations were considered significant at a two-tailed $P^{\mathrm{a}}<0.05$, which were Bonferroni-corrected. Two indicators that were used to assess the strength of evidence were high significance $\left(P^{\mathrm{a}}<0.00001\right)$ and homogeneity or zero heterogeneity $\left(\mathrm{I}^{2}=0 \%\right)$. Analysis models for absence and presence of heterogeneity were fixed-effects [29] and random-effects [30], respectively. Heterogeneity was addressed in the following manner: (i) estimated with the $X^{2}$-based $Q$ test [31] where significance was set at $P_{\text {HET }}<0.10$ [32], (ii) quantified with the $\mathrm{I}^{2}$ statistic, which measures the degree of variability between studies [33] and (iii) its sources examined with outlier treatment using the Galbraith plot [34]. Outlier treatment divided the outcomes into pre-outlier and post-outlier. Robustness of the pooled ORs was assessed with sensitivity analysis, which involved serial omission of the studies followed by re-analysis. Publication bias was assessed with two criteria: (i) statistical significance and (ii) $\geq 10$ studies [35]. Normal or non-normal distribution of the operating data (ORs) warranted use of either Egger's regression asymmetry test [36] or Begg-Mazumdar test of correlation [37]. Data were analyzed using Review Manager 5.3 (Cochrane Collaboration, Oxford, England), SIGMASTAT 2.03 and SIGMAPLOT 11.0 (Systat Software, San Jose, CA).

\section{Results}

\section{Search outcomes}

Figure 1 outlines the study selection process in a flowchart following the Preferred Reporting Items for Systematic Reviews and Meta-Analyses guidelines (Table S2). Twenty-one citations from the initial search were filtered to yield 12 articles for inclusion [38-49], all of

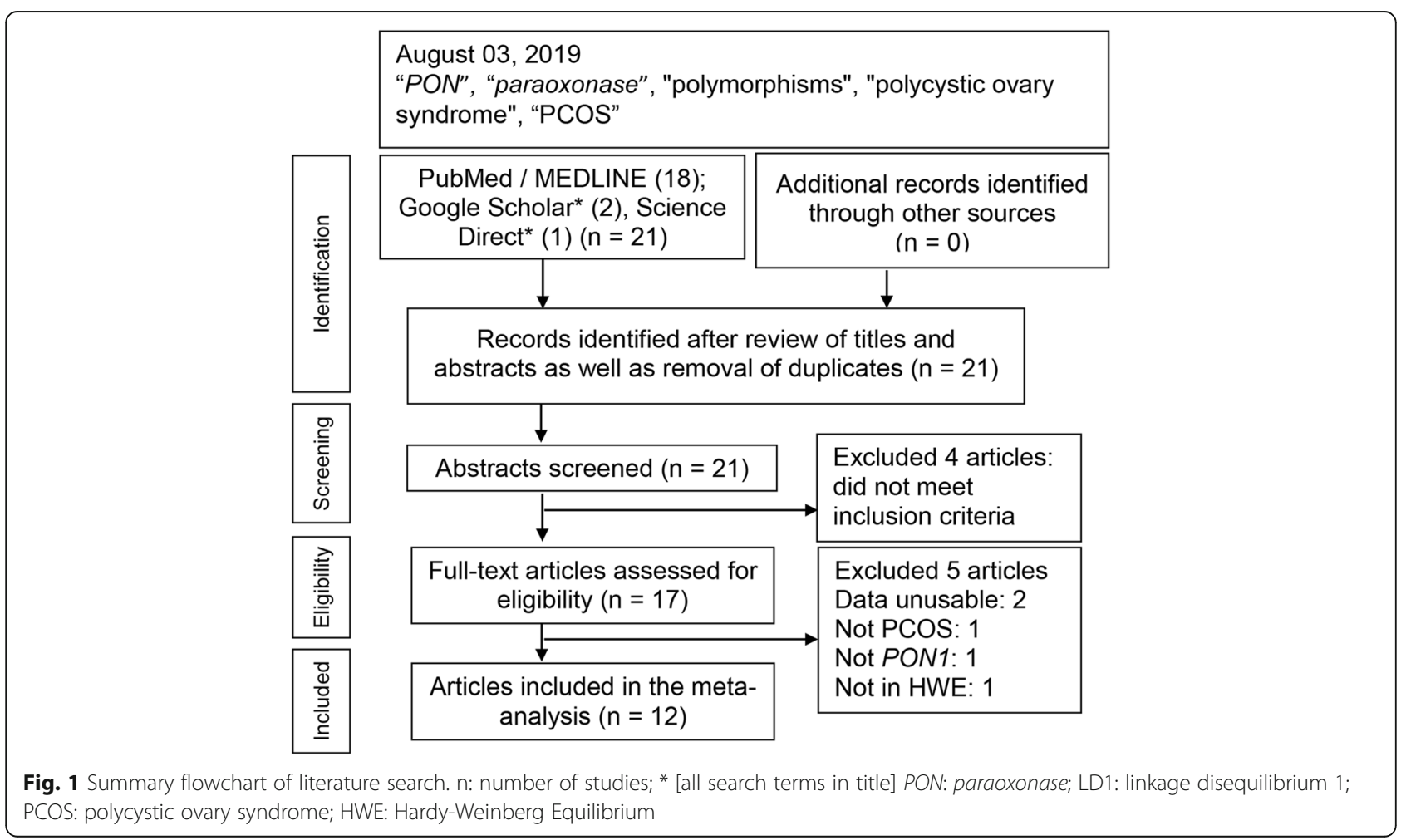


which examined SNVs in PON1 except Liu et al. [48], which focused on rs7493 SNV in PON2.

\section{Characteristics of the included studies}

Table 1 shows which studies were and were not included in the four previous meta-analyses [18-21]. Three articles [47-49] were new additions to the meta-analysis literature and account for the updated associations between $P O N$ variants and PCOS. The sole African study [41] was included in the overall LD2 analysis, but not in LD1 (where it was HWE-deviating) nor in subgroup analysis. Asian and Caucasian subjects were in six and five articles of LD1, in five and three articles of LD2, respectively. Geography of the Asians was clearly dichotomous (China and India), which could have been sub-stratified were it not for issues of multiplicity (risk of falsepositives) and reduced statistical power [50]. Based on the mean \pm standard deviation $(7.17 \pm 1.19)$ of the normally distributed (Shapiro-Wilks test: $P=0.18$ ) Clark-Baudouin scores, methodological quality of the component studies was high. Table S1 shows the unduplicated total sample sizes of the included articles $(n=7092)$, five $[38,39,46-48]$ with adequate statistical power.

\section{Meta-analysis outcomes}

This meta-analysis generated 38 comparisons where 11 significant outcomes were confined to LD1 and LD2 (Tables 2 and 3), consigning PON-PCOS associations to five SNVs (rs854560, rs662, rs705379, rs7493 and rs854572).

\section{LD1 associations with PCOS}

Table 2 shows 15 comparisons for LD1 (rs854560 and rs662), five of which were significant $\left(P^{\mathrm{a}}<0.05\right)$. Of the five, two $\left(P^{\mathrm{a}}<0.0001\right)$ survived the Bonferroni correction, found robust and both indicating increased risk in the var model. One was in the overall analysis seen in Fig. 2 with variable weight contributions of each study that ranged from $0.3 \%$ [44] to $38 \%$ [38], yet yielded a fixed-effects pooled effect (OR 1.44, 95\% CI 1.24-1.67) with low-level heterogeneity $\left(P_{\mathrm{HET}}=0.17, \mathrm{I}^{2}=29 \%\right)$. This pooled effect had no evidence of publication bias (Begg-Mazumdar test: $P=0.19$ ). The other Bonferronisurviving outcome was homogeneous $\left(\mathrm{I}^{2}=0 \%\right)$, and found in Asians (OR 1.41, 95\% CI 1.20-1.65). In contrast to the Asians, Caucasian outcomes were non-significant $\left(P^{\mathrm{a}}=0.44-0.97\right)$. The mechanism of outlier treatment is visualized in the het LD1 overall comparison (Figs. 3, 4 and 5). In the pre-outlier forest plot (Fig. 3), the pooled OR was null (OR 1.00, 95\% CI 0.78-1.28, $\left.P^{\mathrm{a}}=0.97\right)$ and heterogeneous $\left(P_{\mathrm{HET}}=0.0001, \mathrm{I}^{2}=74 \%\right)$. Using the Galbraith plot, we identified the outlier [44] located above the +2 confidence limit (Fig. 4). The post-outlier plot (Fig. 5) showed reduced risk (OR 0.85, 95\% CI 0.76$0.96)$ with eliminated heterogeneity $\left(P_{\mathrm{HET}}=0.60, \mathrm{I}^{2}=\right.$ $0 \%)$, acquired significance $\left(P^{\mathrm{a}}<0.008\right)$, found robust and no evidence of publication bias (Eggers test: $P=0.53$ ).

Table 1 Characteristics of the included studies that examined associations of PON single nucleotide variants with PCOS

\begin{tabular}{|c|c|c|c|c|c|c|c|c|c|c|c|c|}
\hline & \multicolumn{4}{|c|}{$\begin{array}{l}\text { Included in previous meta- } \\
\text { analyses }\end{array}$} & \multirow[t]{2}{*}{$\begin{array}{l}\text { First } \\
\text { author }\end{array}$} & \multirow[t]{2}{*}[\mathrm{R}]{} & \multirow[t]{2}{*}{ Year } & \multirow[t]{2}{*}{ Country } & \multirow[t]{2}{*}{ Ethnicity } & \multirow[t]{2}{*}{$\begin{array}{l}\text { Diagnostic } \\
\text { criteria }\end{array}$} & \multirow[t]{2}{*}{ PON1 variants } & \multirow{2}{*}{$\begin{array}{l}\text { Clark- } \\
\text { Baudouir } \\
\text { score }\end{array}$} \\
\hline & $\begin{array}{l}\text { Liu } \\
{[21]}\end{array}$ & $\begin{array}{l}\text { Liao } \\
{[20]}\end{array}$ & $\begin{array}{l}\mathrm{Gu} \\
{[19]}\end{array}$ & $\begin{array}{l}\text { Chen } \\
{[18]}\end{array}$ & & & & & & & & \\
\hline 1 & yes & yes & no & yes & San Millan & {$[40]$} & 2004 & Spain & Caucasian & $\begin{array}{l}\text { National Institute } \\
\text { of Health }\end{array}$ & rs85460, rs662, rs705379 & 8 \\
\hline 2 & no & yes & no & no & Mohammed & {$[41]$} & 2009 & Egypt & African & $\begin{array}{l}\text { National Institute } \\
\text { of Health }\end{array}$ & rs $854560^{a}$, rs 705379 & 5 \\
\hline 3 & yes & yes & yes & yes & Lenarcik & {$[42]$} & 2010 & Poland & Caucasian & Rotterdam & rs854560 & 6 \\
\hline 4 & yes & yes & no & no & Zhang $(C h)$ & {$[43]$} & 2011 & China & Asian & Rotterdam & rs705379 & 6 \\
\hline 5 & yes & yes & yes & yes & Wang & {$[38]$} & 2012 & China & Asian & Rotterdam & rs854560, rs662 & 7 \\
\hline 6 & yes & yes & yes & yes & Paltoglu & {$[44]$} & 2013 & Greece & Caucasian & $\begin{array}{l}\text { National Institute } \\
\text { of Health }\end{array}$ & rs662, rs705379 & 8 \\
\hline 7 & yes & yes & yes & yes & Ferk & {$[45]$} & 2014 & Slovenia & Caucasian & Rotterdam & rs705379 & 6 \\
\hline 8 & yes & yes & yes & yes & Dadachanji & {$[46]$} & 2015 & India & Asian & Rotterdam & rs854560, rs662 & 8 \\
\hline 9 & yes & yes & yes & yes & Zhang & {$[39]$} & 2015 & China & Asian & Rotterdam & rs854560, rs662, rs705379 & 7 \\
\hline 10 & no & no & no & no & Dadachanji & {$[47]$} & 2018 & India & Asian & Rotterdam & $\begin{array}{l}\text { rs } 705379, \text { rs } 854571, \text { rs } 854572, \\
\text { rs } 854573, \text { rs } 705381\end{array}$ & 8 \\
\hline 11 & no & no & no & no & Liu & {$[48]$} & 2019 & China & Asian & Rotterdam & rs7493 (PON2) & 9 \\
\hline 12 & no & no & no & no & Nalkiran & {$[49]$} & 2019 & Turkey & Caucasian & Rotterdam & rs854560, rs662 ${ }^{a}$ & 8 \\
\hline
\end{tabular}

PON Paraoxonase, PCOS polycystic ovary syndrome, $(\mathrm{Ch})$ Chinese language, $[\mathrm{R}]$ reference number

${ }^{a}$ control frequencies deviated from the Hardy-Weinberg Equilibrium 
Table 2 Overall and ethnic subgroup summary effects of the LD1 PON variants with PCOS

\begin{tabular}{|c|c|c|c|c|c|c|c|c|c|c|c|c|c|c|}
\hline \multirow{3}{*}{$\begin{array}{l}\text { Comparison } \\
\text { Genetic } \\
\text { model } \\
\text { number of } \\
\text { cases/ } \\
\text { controls } \\
\text { (pre-outlier) }\end{array}$} & \multirow[t]{2}{*}{$n$} & \multicolumn{3}{|c|}{ Test of association } & \multicolumn{3}{|c|}{ Test of heterogeneity } & \multirow[t]{2}{*}{$n$} & \multicolumn{3}{|c|}{ Test of association } & \multicolumn{3}{|c|}{ Test of heterogeneity } \\
\hline & & $\overline{\mathrm{OR}}$ & $95 \% \mathrm{Cl}$ & $P^{\mathrm{a}}$ & $\overline{P_{\text {HET }}}$ & $I^{2}(\%)$ & $\begin{array}{l}\text { Analysis } \\
\text { model }\end{array}$ & & $\overline{\mathrm{OR}}$ & $95 \% \mathrm{Cl}$ & $P^{a}$ & $\overline{P_{\text {HET }}}$ & $I^{2}(\%)$ & $\begin{array}{l}\text { Analysi } \\
\text { model }\end{array}$ \\
\hline & \multicolumn{7}{|c|}{ Pre-outlier } & \multicolumn{7}{|c|}{ Post-outlier } \\
\hline \multicolumn{15}{|l|}{ Overall } \\
\hline \multicolumn{15}{|l|}{$2114 / 1588$} \\
\hline var & 11 & 1.44 & $1.24-1.67$ & $0.00001^{*} † \ddagger$ & 0.17 & 29 & Fixed & - & - & - & - & - & - & - \\
\hline$w t$ & 11 & 0.81 & $0.57-1.17$ & 0.26 & 0.00001 & 85 & Random & 10 & 0.90 & $0.84-1.10$ & 0.59 & 0.16 & 31 & Fixed \\
\hline het & 11 & 1.00 & $0.78-1.28$ & 0.97 & 0.0001 & 74 & Random & 10 & 0.85 & $0.76-0.96$ & $0.008+$ & 0.60 & 0 & Fixed \\
\hline \multicolumn{15}{|l|}{ Asian } \\
\hline \multicolumn{15}{|l|}{$1547 / 1270$} \\
\hline var & 6 & 1.41 & $1.20-1.65$ & $0.0001^{*}+\ddagger$ & 0.99 & 0 & Fixed & - & - & - & - & - & - & - \\
\hline$w t$ & 6 & 0.94 & $0.74-1.20$ & 0.62 & 0.03 & 60 & Random & 5 & 0.83 & $0.80-0.98$ & 0.03 & 0.48 & 0 & Fixed \\
\hline het & 6 & 0.84 & $0.74-0.96$ & 0.008 & 0.42 & 0 & Fixed & - & - & - & - & - & - & - \\
\hline \multicolumn{15}{|l|}{ Caucasian } \\
\hline \multicolumn{15}{|l|}{$567 / 318$} \\
\hline var & 5 & 1.39 & $0.55-3.51$ & 0.49 & 0.005 & 73 & Random & 4 & 1.01 & $0.63-1.61$ & 0.97 & 0.36 & 6 & Fixed \\
\hline$w t$ & 5 & 0.67 & $0.24-1.84$ & 0.44 & 0.0001 & 91 & Random & 4 & 1.09 & $0.77-1.53$ & 0.63 & 1.00 & 0 & Fixed \\
\hline het & 5 & 1.30 & $0.60-2.75$ & 0.49 & 0.001 & 84 & Random & 4 & 0.91 & $0.65-1.29$ & 0.61 & 0.52 & 0 & Fixed \\
\hline
\end{tabular}

LD linkage disequilibrium, LD1 (rs854560 + rs662), PON Paraoxonase, PCOS polycystic ovary syndrome, var variant, wt wild-type, het heterozygous genotype $(v a r+w t), n$ number of studies, OR odds ratio, $\mathrm{Cl}$ confidence interval, $P^{\mathrm{a}} P$-value for association, $P_{\mathrm{HET}} P$-value for heterogeneity, $\mathrm{I}^{2}$ measure of variability; values in bold indicate significant associations; *survived the Bonferroni correction; † without evidence of publication bias; $\neq$ robust

However, this post-outlier pooled effect did not survive the Bonferroni correction.

\section{LD2 and LD3 associations with PCOS}

Table 3 shows 18 comparisons for LD2 (rs705379, rs7493 and rs854572), six of which were significant $\left(P^{\mathrm{a}}=\right.$ 0.005-0.03) with none surviving the Bonferroni correction. Of the six, two indicated reduced risks in the recessive and codominant models, both in power analysis (ORs 0.77-0.82, 95\% CIs 0.62-0.97, $P^{\mathrm{a}}=0.002-0.02$ ). In contrast, the remaining four pooled ORs indicated increased risks, three of which were post-outlier derived in the overall analysis (ORs 1.14-1.34, 95\% CIs 1.02-1.64, $\left.P^{\mathrm{a}}=0.005-0.03\right)$ and one in the pre-outlier Caucasian subgroup of the codominant model (OR 1.32, 95\% CI 1.05-1.67, $\left.P^{\mathrm{a}}=0.02\right)$. Table 3 shows five comparisons for LD3, none of which were significant $\left(P^{\mathrm{a}}>0.05\right)$. Of the five, four had pooled ORs that skirted the null effect (ORs 0.94-1.02).

\section{Discussion}

\section{Summary of findings}

In the main findings, the two LD1 var outcomes met the criterion of high significance. However, only the Asian outcome met the other criterion of homogeneity. Nevertheless, these two core findings identified the $P O N$ rs854560 and rs662 SNVs to be associated with risk of PCOS. The LD groups differed by ethnicity, where a significant codominant risk effect in the LD2 was found in Caucasians (OR 1.32, $P^{\mathrm{a}}=0.02$ ) but not in Asians (OR $1.03, P^{\mathrm{a}}=0.59$ ). In LD1, on the other hand, significant risk effects were found in all genetic models in Asians $\left(P^{\mathrm{a}}=0.0001-0.03\right)$ but not in Caucasians ( $P^{\mathrm{a}}=0.44-$ 0.97). Two notes regarding power outcomes (i) LD1 Asian increased risk effects were also powered and homogeneous in the var comparison; and (ii) LD2 power effects were protective (18-23\%) in the recessive and codominant models. Reduced risk effects (15-16\%) were also observed in the het outcomes of LD1 (overall and Asian), where the phenotypic difference (increased risk versus reduced risk) between var and het suggests a heterosis phenomenon. Heterosis occurs when subjects heterozygous for a specific genetic polymorphism show a different phenotype from homozygotes [51], conferring a heterozygote advantage (protection). Variations of these effects between the genetic models and ethnic subgroups suggest complex PON-PCOS associations, which is further driven by interactions between genetic and nongenetic risk factors. Gene-gene and gene-environment interactions have been reported to have roles in the associations of PON variants with PCOS. All 12 included articles acknowledged the role of environment but 
Table 3 Overall, modifier and ethnic subgroup summary effects of the LD2 and LD3 PON variants with PCOS

\begin{tabular}{|c|c|c|c|c|c|c|c|c|c|c|c|c|c|c|}
\hline \multirow{3}{*}{$\begin{array}{l}\text { SNV group } \\
\text { Comparison } \\
\text { Genetic model } \\
\text { number of } \\
\text { cases/controls } \\
\text { (pre-outlier) } \\
\end{array}$} & \multirow[t]{2}{*}{$n$} & \multicolumn{3}{|c|}{ Test of association } & \multicolumn{3}{|c|}{ Test of heterogeneity } & \multirow[t]{2}{*}{$n$} & \multicolumn{3}{|c|}{ Test of association } & \multicolumn{3}{|c|}{ Test of heterogeneity } \\
\hline & & $\overline{\mathrm{OR}}$ & $95 \% \mathrm{Cl}$ & $P^{a}$ & $\overline{P_{\text {HET }}}$ & $I^{2}(\%)$ & $\begin{array}{l}\text { Analysis } \\
\text { model }\end{array}$ & & $\overline{\mathrm{OR}}$ & $95 \% \mathrm{Cl}$ & $P^{\mathrm{a}}$ & $\overline{P_{\text {HET }}}$ & $I^{2}(\%)$ & $\begin{array}{l}\text { Analysis } \\
\text { model }\end{array}$ \\
\hline & \multicolumn{7}{|c|}{$\overline{\text { Pre-outlier }}$} & \multicolumn{7}{|c|}{ Post-outlier } \\
\hline \multicolumn{15}{|l|}{ LD2 } \\
\hline \multicolumn{15}{|c|}{ Overall $(2006 / 1652)$} \\
\hline Recessive & 9 & 1.33 & $0.93-1.88$ & 0.11 & 0.0001 & 77 & Random & 6 & 1.34 & $1.09-1.64$ & 0.005 & 0.21 & 30 & Fixed \\
\hline Dominant & 9 & 1.09 & $0.90-1.31$ & 0.37 & 0.02 & 56 & Random & 7 & 1.16 & $1.02-1.33$ & 0.03 & 0.18 & 32 & Fixed \\
\hline Codominant & 9 & 1.16 & $0.96-1.40$ & 0.12 & 0.0001 & 80 & Random & 6 & 1.14 & $1.03-1.26$ & 0.01 & 0.61 & 0 & Fixed \\
\hline \multicolumn{15}{|c|}{ Power $^{\mathbf{a}}(1448 / 1169)$} \\
\hline Recessive & 3 & 0.77 & $0.62-0.97$ & 0.02 & 0.15 & 48 & Fixed & - & - & - & - & - & - & - \\
\hline Dominant & 3 & 0.93 & $0.81-1.06$ & 0.27 & 0.12 & 52 & Fixed & - & - & - & - & - & - & - \\
\hline Codominant & 3 & 0.90 & $0.74-1.09$ & 0.28 & 0.04 & 70 & Random & 2 & 0.82 & $0.72-0.93$ & 0.002 & 0.63 & 0 & Fixed \\
\hline \multicolumn{15}{|c|}{ Asian $(1794 / 1484)$} \\
\hline Recessive & 5 & 1.05 & $0.78-1.42$ & 0.73 & 0.08 & 55 & Random & 3 & 1.22 & $0.97-1.55$ & 0.09 & 0.81 & 0 & Fixed \\
\hline Dominant & 5 & 1.04 & $0.91-1.18$ & 0.59 & 0.39 & 1 & Fixed & - & - & - & - & - & - & - \\
\hline Codominant & 5 & 1.03 & $0.93-1.13$ & 0.59 & 0.12 & 49 & Fixed & - & - & - & - & - & - & - \\
\hline \multicolumn{15}{|c|}{ Caucasian (118/108) } \\
\hline Recessive & 3 & 1.91 & $0.94-3.89$ & 0.08 & 0.08 & 61 & Random & 2 & 1.39 & $0.89-2.18$ & 0.15 & 0.52 & 0 & Fixed \\
\hline Dominant & 3 & 1.25 & $0.87-1.78$ & 0.22 & 0.84 & 0 & Fixed & - & - & - & - & - & - & - \\
\hline Codominant & 3 & 1.32 & $1.05-1.67$ & 0.02 & 0.46 & 0 & Fixed & - & - & - & - & - & - & - \\
\hline \multicolumn{15}{|l|}{ LD3 } \\
\hline \multicolumn{15}{|c|}{ Overall (516/424) } \\
\hline Recessive & 4 & 1.02 & $0.74-1.40$ & 0.91 & 0.05 & 63 & Random & 3 & 1.2 & $0.95-1.51$ & 0.12 & 0.59 & 0 & Fixed \\
\hline Dominant & 4 & 0.94 & $0.82-1.07$ & 0.32 & 0.44 & 0 & Fixed & - & - & - & - & - & - & - \\
\hline Codominant & 4 & 0.97 & $0.84-1.12$ & 0.66 & 0.08 & 56 & Random & 3 & 1.04 & $0.93-1.17$ & 0.49 & 0.75 & 0 & Fixed \\
\hline
\end{tabular}

SNV single nucleotide variant, LD linkage disequilibrium, LD2 (rs705379 + rs7493 + rs854572), LD3 (rs854571+ rs854572 + rs854573 + rs705381), PON Paraoxonase, PCOS polycystic ovary syndrome; ${ }^{a}$ statistical power $\geq 80 \% ; n$ number of studies, OR odds ratio, $\mathrm{Cl}$ confidence interval, $P$ a $P$-value for association, $P_{\mathrm{HET}} P$-value for heterogeneity, $\mathrm{I}^{2}$ measure of variability; values in bold indicate significant association

haplotype analysis was addressed in only four (33\%) of the component studies [38, 45, 47, 49]. In addition to $P O N$, one article [48] examined SNVs in another gene (superoxide dismutase-2).

The role of PON1 variants with PCOS have been addressed in four meta-analyses [18-21], which we compared with the present study in terms of general features and methodology (Table S3). The previous metaanalyses [18-21] examined PON1 only but our study included PON2 (rs7493) on account of its full LD with rs705379 and rs854572 of PON1. To our knowledge, this is the fifth meta-analysis to address the PON-PCOS associations, but the first to accomplish the following: (i) perform an umbrella review (Table S3); (ii) apply outlier treatment with the most number $(n=12)$ of included articles; and (iii) operate within LD parameters. These features render our study as most comprehensive, managing to accomplish two things: (i) fill the gaps and update the meta-analysis knowledge of the PON SNV-
PCOS associations and (ii) minimize the methodological problems that beset primary studies including limited statistical power, unrecognized confounding factors, misleading definition of phenotypes and stratification of populations [24].

\section{Physiological correlates}

PCOS is a reproductive endocrinopathy [52] that is associated with dyslipidemia, obesity and insulin resistance [53]. These metabolic disorders lead to disease conditions such as hypertension, cardiovascular disease and diabetes mellitus [54]. These disease comorbidities were shown to be related with increased oxidative stress, exhibiting altered physiological conditions such as increased plasma glucose and low antioxidant reserves [55, 56]. Low antioxidant levels in PCOS patients suggest that elevated oxidative status contribute to the battery of cardiometabolic derangements [57]. These perturbations have been attributed to reduced serum PON1 activity in 


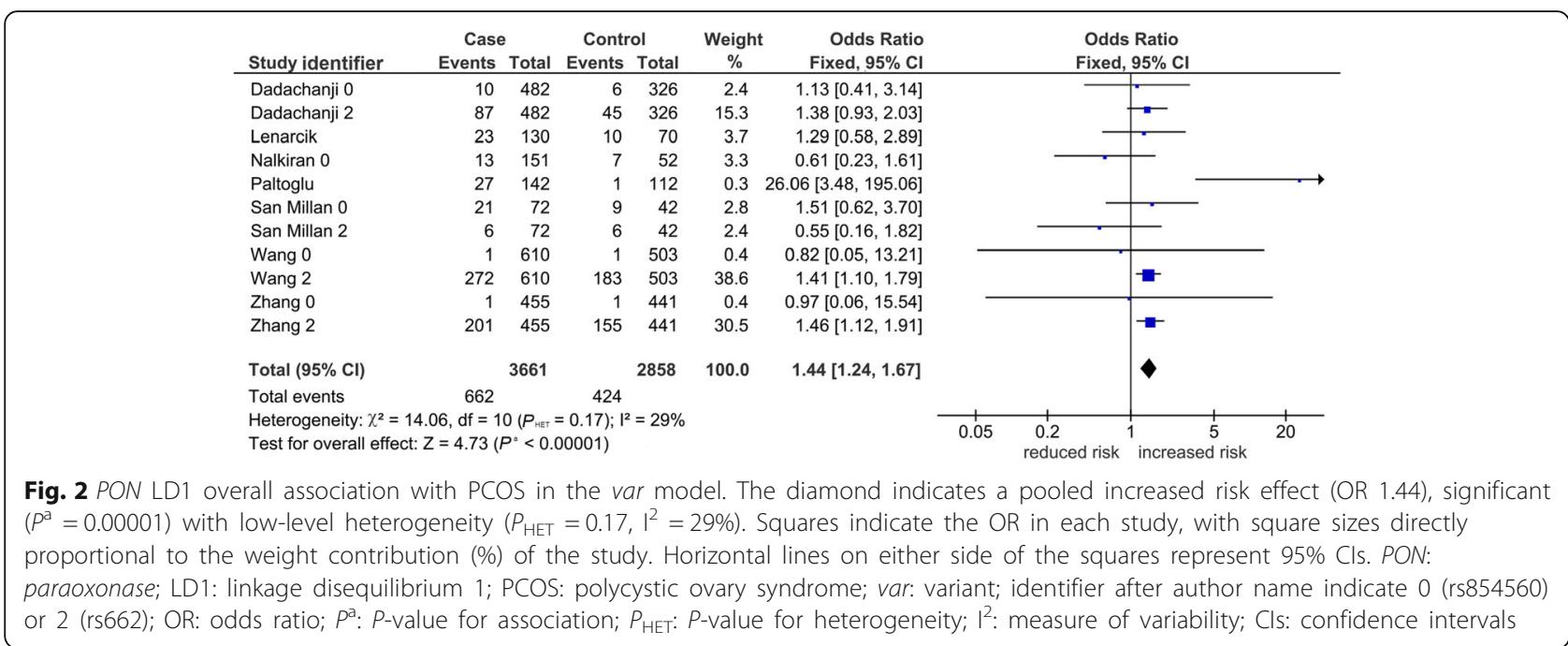

PCOS patients [58], its genetic underpinnings [59] partly explained with the significant findings of our study observed in LD1, involving rs854560 (L55M) and rs662 (Q192R). These two SNVs account for the main PCOS risk associations in this meta-analysis. The rs 854560 variant, not rs662, has been reported to affect enzyme concentration $[15,60]$. Compared to 55LL genotype in rs854560, 55MM carriers have lower enzyme activity, which may be attributed to the correlation between the $55 \mathrm{M}$ allele and reduced mRNA and protein levels [61]. Moreover, strong LD of this variant with rs662 may partly explain the variation in PON1 catalytic activity [62]. Depending on the assay used, the $\mathrm{R}$ allele of rs662 could be associated with increased or decreased PON1 activity [63]. Reduced enzyme activity leads to elevated levels of oxidative stress altering the metabolism in
PCOS patients [64]. Oxidative stress profiles in these patients revealed the $\mathrm{R}$ allele carriers had impaired physiologic responses involving increased oxidization of low-density lipoprotein [46], high triglyceride levels [38] and elevated insulin resistance [44]. Even in the absence of insulin resistance, oxidative stress levels remain high in PCOS women [65]. This cascade of impaired physiological events, as well as inflammatory responses to cellular injuries caused by oxidative stress, primes the pathophysiology of PCOS as inflammatory mediators that have been known to regulate PON expression [66] and contribute to PCOS pathogenesis [67]. Moreover, genetic combination analysis demonstrated that haplotypes containing the 192R allele was significantly associated with PCOS risk ranging from 1.6 to 8 -fold [38, 49]. In sum, the $\mathrm{R}$ allele of rs662 appears to be a genetic

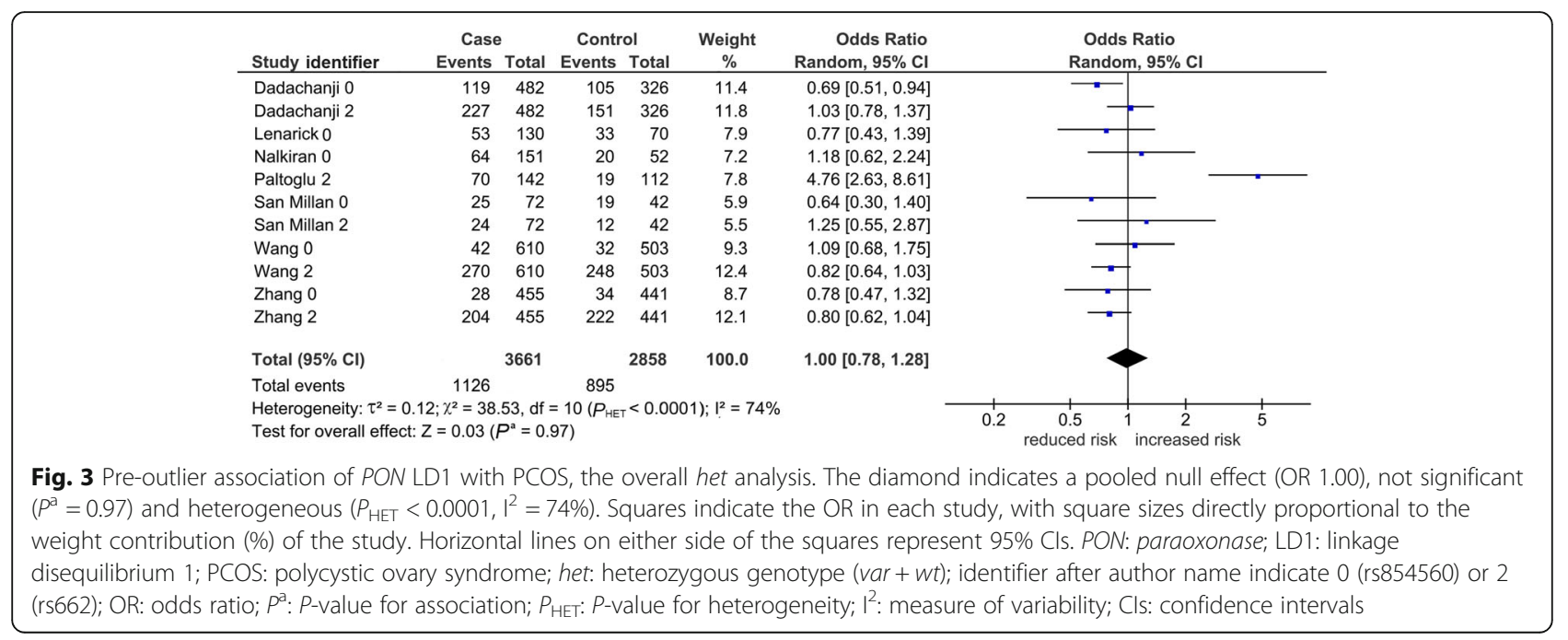




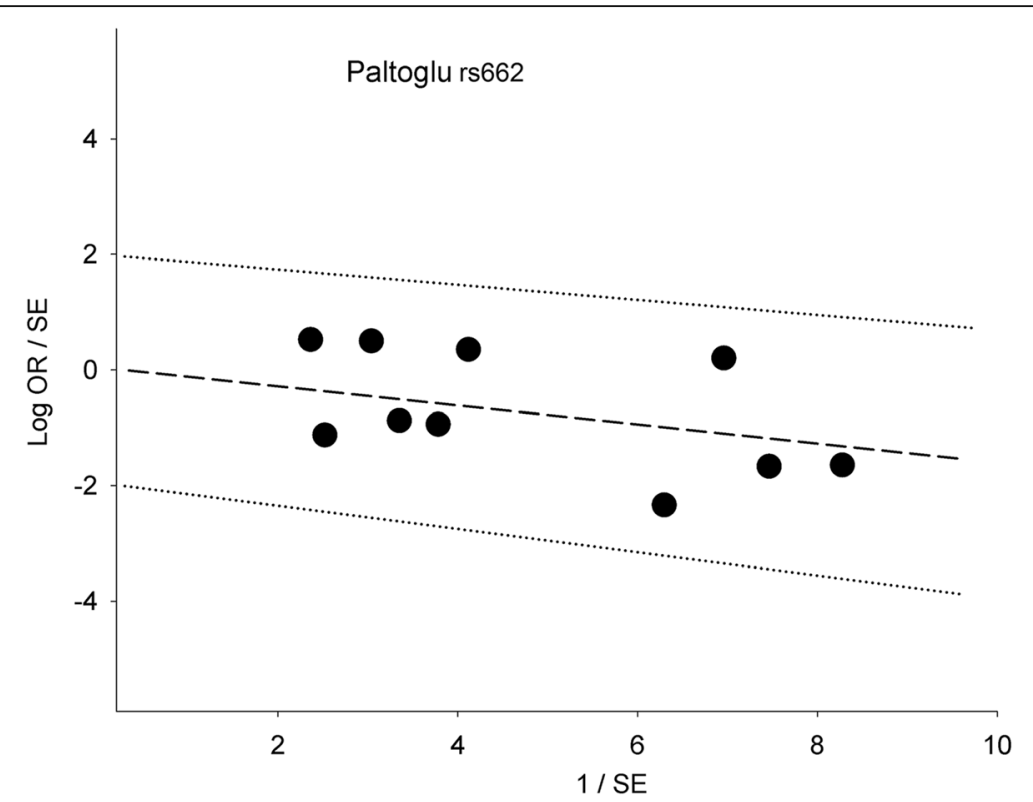

Fig. 4 Galbraith plot analysis of PON LD1 with PCOS, the overall het analysis. The study found above the +2 confidence limit was identified as the outlier. PON: paraoxonase; LD1: linkage disequilibrium 1; PCOS: polycystic ovary syndrome; het: heterozygous genotype (var + wt); OR: odds ratio; SE: standard error; Log OR: logarithm of odds ratio

determinant of PCOS susceptibility in the female population [49]. These genetically susceptible women are the likely candidates who could benefit from the clinical application of our results. PCOS risks along with their comorbidities could be clinically reduced or delayed with modifications of environmental influences meant to reduce levels of oxidative stress.

\section{Strengths and limitations}

Limitations of our study include: (i) six (50\%) of the included primary 12 articles were underpowered.
However, statistical power at the aggregate level was more than adequate and (ii) credible subgrouping was suggested at no more than two levels [50], which left other possible subgroups (e.g. diagnostic criteria) unexamined. On the other hand, strengths of this metaanalysis are: (i) the combination of more studies, larger sample sizes and multiple meta-analysis treatments raised the level of evidence presented in this study; (ii) restricting our analysis to HW-compliant studies minimized the risk of representation and methodological bias [28]; (iii) potency of outlier treatment is evidenced from

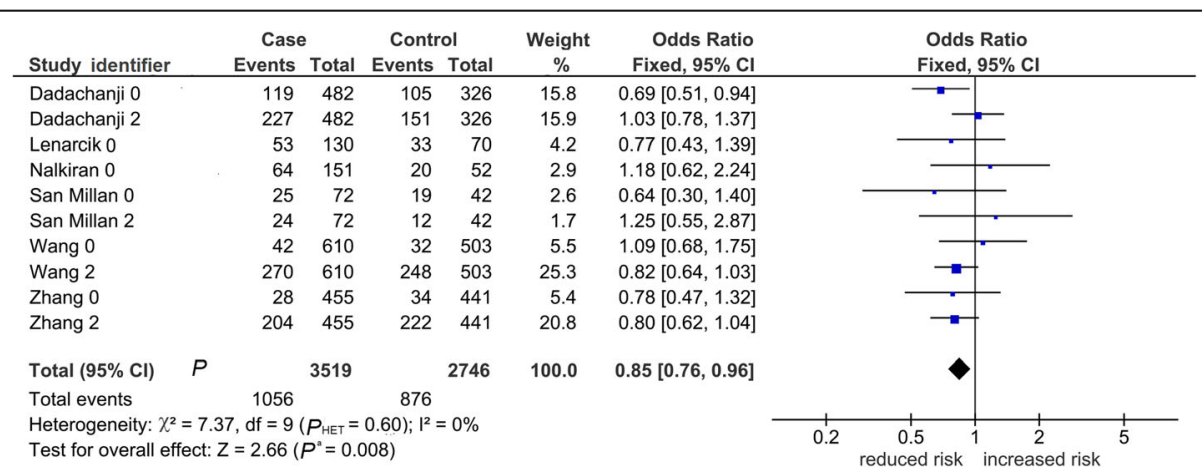

Fig. 5 Post-outlier association of PON LD1 with PCOS, the overall het analysis. The diamond shows the pooled effect indicating decreased risk (OR $0.85)$, which was significant $\left(P^{\mathrm{a}}=0.008\right)$ and homogeneous $\left(P_{\mathrm{HET}}=0.60, \mathrm{I}^{2}=0 \%\right)$. Squares indicate the $\mathrm{OR}$ in each study, with square sizes directly proportional to the weight contribution (\%) of the study. Horizontal lines on either side of the squares represent 95\% Cls. PON: paraoxonase; LD1: linkage disequilibrium 1; PCOS: polycystic ovary syndrome; het: heterozygous genotype $(v a r+w t)$; OR: identifier after author name indicate 0 (rs854560) or 2 (rs662); odds ratio; $P^{\mathrm{a}}$ : $P$-value for association; $P_{\text {HET: }} P$-value for heterogeneity; $I^{2}$ : measure of variability; Cls: confidence intervals 
the LD1 and LD2 analyses, where six (50\%) and eight (67\%) of the 12 combined post-outlier comparisons were acquired significance and eliminated heterogeneity (Tables 2 and 3); (iv) the overall methodological quality (determined by the Clark-Baudouin Scale) of the included articles was high; (iv) all genotyping used polymerase chain reaction followed by either restriction fragment length polymorphism (11/12 articles) or direct sequencing (1/12 articles) techniques, indicating low-level heterogeneity; (v) all tissue samples were from blood, indicating source homogeneity and (vi) umbrella review of previous meta-analyses enabled comparisons of methodological treatments and findings (Table S3). This provided insight into the evolving consolidation of knowledge into the association genetics of PCOS involving the PON SNVs.

\section{Conclusions}

Bonferroni-corrected significance identified rs854560 and rs662 (LD1) as the PON variants associated with PCOS. Subgrouping delineated ethnic-specific effects rendering var carrier Asians susceptible. Future studies exploring other ethnic groups would substantiate conclusions on these PON-PCOS associations with sample sizes appropriate for detecting small genotypic risks.

\section{Supplementary Information}

The online version contains supplementary material available at https://doi. org/10.1186/s12958-020-00665-1.

Additional file 1: Table S1. Quantitative features of the included PONPCOS studies. Table S2. Preferred Reporting Items for Systematic Reviews and Meta-Analyses checklist. Table S3. Comparisons between meta-analyses that examined the PON variants associations with PCOS.

\section{Acknowledgements}

We thank Jakkree Tangthianchaichana for acquiring the key literature.

\section{Authors' contributions}

AK, NP and BB conceived the study topic. NP designed the methodology. AK and NP extracted the data. AK and BB validated the data. NP and EM performed the statistics. AK, NP and BB performed quality assessment of the studies. NP and HJ discussed the linkage disequilibrium issue. NP, DMC and CPB discussed the applications for genetic modeling. BB supervised the project. $\mathrm{HJ}$ and EM provided the software. AK and NP wrote the original draft. AK, DMC and CPB edited and reviewed the subsequent drafts. AK, NP and BB wrote the final draft. All authors read and approved the final manuscript.

\section{Funding}

The authors declare that this study was unfunded.

\section{Availability of data and materials}

All data generated or analyzed during this study are included in the supplementary information files.

\section{Ethics approval and consent to participate}

Not applicable.

\section{Consent for publication}

Not applicable.

\section{Competing interests}

The authors declare that they have no competing interests.

\section{Author details}

${ }^{1}$ Chulabhorn International College of Medicine, Thammasat University, Khlong Luang District, Rangsit, Pathumthani, Thailand. ${ }^{2}$ Environmental Monitoring and Reporting Branch, Ontario Ministry of the Environment, Conservation and Parks, 125 Resources Road, Toronto, Ontario, Canada. ${ }^{3}$ Human Reproduction and Genetics Center, Department of Collective Health, Faculdade de Medicina do ABC, Santo André, SP, Brazil.

Received: 22 October 2019 Accepted: 26 October 2020

Published online: 20 November 2020

\section{References}

1. Goodarzi MO, Dumesic DA, Chazenbalk G, Azziz R. Polycystic ovary syndrome: etiology, pathogenesis and diagnosis. Nat Rev Endocrinol. 2011;7:219-31.

2. Jones MR, Goodarzi MO. Genetic determinants of polycystic ovary syndrome: progress and future directions. Fertil Steril. 2016;106:25-32.

3. Murri M, Luque-Ramirez M, Insenser M, Ojeda-Ojeda M, Escobar-Morreale HF. Circulating markers of oxidative stress and polycystic ovary syndrome (PCOS): a systematic review and meta-analysis. Hum Reprod Update. 2013; 19:268-88.

4. Liu J, Zhang D. The role of oxidative stress in the pathogenesis of polycystic ovary syndrome. Sichuan Da Xue Xue Bao Yi Xue Ban. 2012; 43:187-90.

5. Rodrigues JK, Dib LA, Ferriani RA, Jordao Junior AA, Navarro PA. Serum markers of oxidative stress and assisted reproduction procedures results in infertile patients with polycystic ovary syndrome and controls. Rev Bras Ginecol Obstet. 2010;32:118-25.

6. Agarwal A, Gupta S, Sharma R. Oxidative stress and its implications in female infertility - a clinician's perspective. Reprod BioMed Online. 2005;11: 641-50

7. Precourt LP, Amre D, Denis MC, Lavoie JC, Delvin E, Seidman E, Levy E. The three-gene paraoxonase family: physiologic roles, actions and regulation. Atherosclerosis. 2011;214:20-36

8. Ng CJ, Shih DM, Hama SY, Villa N, Navab M, Reddy ST. The paraoxonase gene family and atherosclerosis. Free Radic Biol Med. 2005;38:153-63.

9. Mochizuki H, Scherer SW, Xi T, Nickle DC, Majer M, Huizenga JJ, Tsui LC, Prochazka M. Human PON2 gene at 7q21.3: cloning, multiple mRNA forms, and missense polymorphisms in the coding sequence. Gene. 1998:213:149-57.

10. Chen Q, Reis SE, Kammerer CM, McNamara DM, Holubkov R, Sharaf BL, Sopko G, Pauly DF, Merz CN, Kamboh MI, Group WS. Association between the severity of angiographic coronary artery disease and paraoxonase gene polymorphisms in the National Heart, Lung, and Blood Institute-sponsored Women's Ischemia Syndrome Evaluation (WISE) study. Am J Hum Genet. 2003;72:13-22.

11. Saeed M, Perwaiz labal M, Yousuf FA, Perveen S, Shafiq M, Sajid J, Frossard PM. Interactions and associations of paraoxonase gene cluster polymorphisms with myocardial infarction in a Pakistani population. Clin Genet. 2007;71:238-44.

12. San Millan JL, Alvarez-Blasco F, Luque-Ramirez M, Botella-Carretero ال Escobar-Morreale HF. The PON1-108C/T polymorphism, and not the polycystic ovary syndrome, is an important determinant of reduced serum paraoxonase activity in premenopausal women. Hum Reprod. 2006;21: 3157-61.

13. Brophy VH, Jampsa RL, Clendenning JB, McKinstry LA, Jarvik GP, Furlong CE. Effects of $5^{\prime}$ regulatory-region polymorphisms on paraoxonase-gene (PON1) expression. Am J Hum Genet. 2001;68:1428-36.

14. Rajkovic MG, Rumora L, Barisic K. The paraoxonase 1, 2 and 3 in humans. Biochem Med (Zagreb). 2011;21:122-30

15. Leviev I, James RW. Promoter polymorphisms of human paraoxonase PON1 gene and serum paraoxonase activities and concentrations. Arterioscler Thromb Vasc Biol. 2000;20:516-21.

16. Suehiro T, Nakamura T, Inoue M, Shiinoki T, Ikeda Y, Kumon Y, Shindo M, Tanaka H, Hashimoto K. A polymorphism upstream from the human paraoxonase (PON1) gene and its association with PON1 expression. Atherosclerosis. 2000;150:295-8. 
17. Deakin S, Leviev I, Brulhart-Meynet MC, James RW. Paraoxonase-1 promoter haplotypes and serum paraoxonase: a predominant role for polymorphic position - 107, implicating the Sp1 transcription factor. Biochem J. 2003:372:643-9.

18. Chen B, Wang Y, Lin W, Jiang H, Liu C, Dong C, Gu H, Kang M, Tang W. Association between paraoxonase-1 (PON-1) polymorphisms and polycystic ovary syndrome susceptibility: a meta-analysis. Int J Clin Exp Med. 2016;9: 1490-9.

19. Gu HF, Mou M, Liang ZG, Sun C, Ren XY, Xiao YB. The association between paraoxonase 1 gene polymorphisms and polycystic ovarian syndrome. Cell Mol Biol (Noisy-le-grand). 2016;62:44-7.

20. Liao D, Yu H, Han L, Zhong C, Ran X, Wang D, Mo L. Association of PON1 gene polymorphisms with polycystic ovarian syndrome risk: a meta-analysis of case-control studies. J Endocrinol Investig. 2018;41:1289-300.

21. Liu L, Yang J, Liu Q, Yan W, Wen Y. Risk association of polycystic ovary syndrome with paraoxonase 1 and TNF-a gene polymorphisms: a metaanalysis. Int J Clin Exp Med. 2016:9:7088-101.

22. Faul F, Erdfelder E, Lang A, Buchner A. G*Power 3: a flexible statistical power analysis program for the social, behavioral, and biomedical sciences. Behav Res Methods. 2007;39:175-91.

23. Ghasemi A, Zahediasl S. Normality tests for statistical analysis: a guide for non-statisticians. Int J Endocrinol Metab. 2012;10:486-9.

24. Clark MF, Baudouin SV. A systematic review of the quality of genetic association studies in human sepsis. Intensive Care Med. 2006;32:1706-12.

25. Infante-Rivard C. Genetic association between single nucleotide polymorphisms in the paraoxonase 1 (PON1) gene and small-forgestational-age birth in related and unrelated subjects. Am J Epidemiol. 2010;171:999-1006.

26. Lewontin RC. On measures of gametic disequilibrium. Genetics. 1988;120: 849-52.

27. Pereira TV, Patsopoulos NA, Pereira AC, Krieger JE. Strategies for genetic model specification in the screening of genome-wide meta-analysis signals for further replication. Int J Epidemiol. 2011;40:457-69.

28. Trikalinos TA, Salanti G, Khoury MJ, Ioannidis JP. Impact of violations and deviations in Hardy-Weinberg equilibrium on postulated gene-disease associations. Am J Epidemiol. 2006:163:300-9.

29. Mantel N, Haenszel W. Statistical aspects of the analysis of data from retrospective studies of disease. J Natl Cancer Inst. 1959;22:719-48,

30. DerSimonian R, Laird N. Meta-analysis in clinical trials. Control Clin Trials. 1986;7:177-88

31. Lau J, loannidis JP, Schmid CH. Quantitative synthesis in systematic reviews. Ann Intern Med. 1997;127:820-6.

32. Higgins JP, Thompson SG, Deeks JJ, Altman DG. Measuring inconsistency in meta-analyses. BMJ. 2003;327:557-60.

33. Higgins JP, Thompson SG. Quantifying heterogeneity in a meta-analysis. Stat Med. 2002;21:1539-58.

34. Galbraith RF. A note on graphical presentation of estimated odds ratios from several clinical trials. Stat Med. 1988;7:889-94.

35. Ioannidis JP, Trikalinos TA. The appropriateness of asymmetry tests for publication bias in meta-analyses: a large survey. CMAJ. 2007;176:1091-6.

36. Egger M, Davey Smith G, Schneider M, Minder C. Bias in meta-analysis detected by a simple, graphical test. BMJ. 1997;315:629-34.

37. Begg CB, Mazumdar M. Operating characteristics of a rank correlation test for publication bias. Biometrics. 1994;50:1088-101.

38. Wang Y, Liu H, Fan P, Bai H, Zhang J, Zhang F. Evidence for association between paraoxonase 1 gene polymorphisms and polycystic ovarian syndrome in southwest Chinese women. Eur J Endocrinol. 2012;166: 877-85.

39. Zhang Y, Liu H, He J, Xu K, Bai H, Wang Y, Zhang F, Zhang J, Cheng L, Fan $P$. Lactonase activity and status of paraoxonase 1 in Chinese women with polycystic ovarian syndrome. Eur J Endocrinol. 2015;172:391-402.

40. San Millan JL, Corton M, Villuendas G, Sancho J, Peral B, Escobar-Morreale HF. Association of the polycystic ovary syndrome with genomic variants related to insulin resistance, type 2 diabetes mellitus, and obesity. J Clin Endocrinol Metab. 2004;89:2640-6.

41. Mohamed AA, Rashed LA, Abdel Salam RF. Effect of paraoxonase gene polymorphisms on paraoxonase levels and insulin resistance index in women with polycystic ovary syndrome. Aust J Basic Appl Sci. 2009;3: 3346-51.

42. Lenarcik A, Bidzinska-Speichert B, Tworowska-Bardzinska U. The role of chronic inflammation and Leu55Met PON1 polymorphism in the pathogenesis of polycystic ovary syndrome. Gynecol Endocrinol. 2010;26: 673-83.

43. Zhang F, Liu HW, Fan P, Bai H, Song Q. The $-108 \mathrm{C} / \mathrm{T}$ polymorphism in paraoxonase 1 gene in Chinese patients with polycystic ovary syndrome. Sichuan Da Xue Xue Bao Yi Xue Ban. 2011;42:24-8.

44. Paltoglou G, Tavernarakis G, Christopoulos P, Vlassi M, Gazouli M, Deligeoroglou E, Creatsas G, Mastorakos G. PON1-108 TT and PON1-192 RR genotypes are more frequently encountered in Greek PCOS than non-PCOS women, and are associated with hyperandrogenaemia. Clin Endocrinol. 2013;79:259-66.

45. Ferk P, Gersak K. Association of -108 C >T PON1 polymorphism with polycystic ovary syndrome. Biomed Rep. 2014;2:255-9.

46. Dadachanji R, Shaikh N, Khavale S, Patil A, Shah N, Mukherjee S. PON1 polymorphisms are associated with polycystic ovary syndrome susceptibility, related traits, and PON1 activity in Indian women with the syndrome. Fertil Steril. 2015;104:207-16.

47. Dadachanji R, Shaikh N, Patil A, Shah N, Mukherjee S. PON1 promoter polymorphisms contribute to PCOS susceptibility and phenotypic outcomes in Indian women. Gene. 2018:661:34-44.

48. Liu Q, Liu H, Bai H, Huang W, Zhang R, Tan J, Guan L, Fan P. Association of SOD2 A16V and PON2 S311C polymorphisms with polycystic ovary syndrome in Chinese women. J Endocrinol Investig. 2019:42:909-21.

49. Nalkiran HS, Sahin SB, Ayaz T, Nalkiran I, Guzel Al, Eldes T, Yildiz Y. Association of paraoxonase-1 L55M and Q192R polymorphisms with PCOS risk and potential risk factors for atherosclerosis. Biomark Med. 2019;13:279-89.

50. Burke JF, Sussman JB, Kent DM, Hayward RA. Three simple rules to ensure reasonably credible subgroup analyses. BMJ. 2015;351:h5651.

51. Comings DE, MacMurray JP. Molecular heterosis: a review. Mol Genet Metab. 2000;71:19-31.

52. Carmina E, Lobo RA. Polycystic ovary syndrome (PCOS): arguably the most common endocrinopathy is associated with significant morbidity in women. J Clin Endocrinol Metab. 1999:84:1897-9.

53. Gonzalez F, Rote NS, Minium J, Kirwan JP. Evidence of proatherogenic inflammation in polycystic ovary syndrome. Metabolism. 2009;58:954-62.

54. Schroeder BM, American College of O, Gynecologists. ACOG releases guidelines on diagnosis and management of polycystic ovary syndrome. Am Fam Physician. 2003;67:1619-20 1622.

55. Baskol G, Aygen E, Erdem F, Caniklioglu A, Narin F, Sahin Y, Kaya T. Assessment of paraoxonase 1, xanthine oxidase and glutathione peroxidase activities, nitric oxide and thiol levels in women with polycystic ovary syndrome. Acta Obstet Gynecol Scand. 2012;91:326-30.

56. Sabuncu T, Vural H, Harma M, Harma M. Oxidative stress in polycystic ovary syndrome and its contribution to the risk of cardiovascular disease. Clin Biochem. 2001;34:407-13.

57. Fenkci V, Fenkci S, Yilmazer M, Serteser M. Decreased total antioxidant status and increased oxidative stress in women with polycystic ovary syndrome may contribute to the risk of cardiovascular disease. Fertil Steril. 2003:80:123-7.

58. Marsillach J, Checa MA, Pedro-Botet J, Carreras R, Joven J, Camps J. Paraoxonase- 1 in female infertility: a possible role against oxidative stressinduced inflammation. Fertil Steril. 2010;94:1132-4.

59. Aviram M, Rosenblat M, Bisgaier CL, Newton RS, Primo-Parmo SL, La Du BN. Paraoxonase inhibits high-density lipoprotein oxidation and preserves its functions. A possible peroxidative role for paraoxonase. J Clin Invest. 1998; 101:1581-90.

60. Garin MC, James RW, Dussoix P, Blanche H, Passa P, Froguel P, Ruiz J. Paraoxonase polymorphism Met-Leu54 is associated with modified serum concentrations of the enzyme. A possible link between the paraoxonase gene and increased risk of cardiovascular disease in diabetes. J Clin Invest. 1997;99:62-6.

61. Brophy VH, Jarvik GP, Richter RJ, Rozek LS, Schellenberg GD, Furlong CE. Analysis of paraoxonase (PON1) L55M status requires both genotype and phenotype. Pharmacogenetics. 2000;10:453-60.

62. Roest $M$, van Himbergen $T M$, Barendrecht $A B$, Peeters $P H$, van der Schouw YT, Voorbij HA. Genetic and environmental determinants of the PON-1 phenotype. Eur J Clin Investig. 2007;37:187-96.

63. Ginsberg G, Neafsey P, Hattis D, Guyton KZ, Johns DO, Sonawane B. Genetic polymorphism in paraoxonase 1 (PON1): population distribution of PON1 activity. J Toxicol Environ Health B Crit Rev. 2009;12:473-507. 
64. Mohamadin AM, Habib FA, Elahi TF. Serum paraoxonase 1 activity and oxidant/antioxidant status in Saudi women with polycystic ovary syndrome. Pathophysiology. 2010;17:189-96.

65. Torun AN, Vural M, Cece H, Camuzcuoglu H, Toy H, Aksoy N. Paraoxonase-1 is not affected in polycystic ovary syndrome without metabolic syndrome and insulin resistance, but oxidative stress is altered. Gynecol Endocrinol. 2011;27:988-92

66. Fuhrman B. Regulation of hepatic paraoxonase-1 expression. J Lipids. 2012; 2012:684010.

67. Rosenfield RL, Ehrmann DA. The pathogenesis of polycystic ovary syndrome (PCOS): the hypothesis of PCOS as functional ovarian hyperandrogenism revisited. Endocr Rev. 2016;37:467-520.

\section{Publisher's Note}

Springer Nature remains neutral with regard to jurisdictional claims in published maps and institutional affiliations.

Ready to submit your research? Choose BMC and benefit from:

- fast, convenient online submission

- thorough peer review by experienced researchers in your field

- rapid publication on acceptance

- support for research data, including large and complex data types

- gold Open Access which fosters wider collaboration and increased citations

- maximum visibility for your research: over $100 \mathrm{M}$ website views per year

At BMC, research is always in progress.

Learn more biomedcentral.com/submissions 